\title{
Correspondence
}

\section{Self-damage in patients with Klinefelter's Syndrome}

Dear Sirs

It was interesting to read the letter from Professor Priest and his colleagues (Bulletin, July 1984, 8, 140). I have encountered a young man, aged 33, of dull, normal intelligence, who has been diagnosed as Klinefelter's Syndrome. He is a single, obese man. with sparsely distributed body hair, marked gynaecomastia, and under-developed genitals. He has a long history of self-mutilation which includes cutting himself with razor blades and glass, swallowing glass pieces, safety pins and stones, and at times re-opening operation scars. He has undergone multiple laparotomies and shows extensive skin scarring in both arms and abdomen. He has also taken repeated overdoses, and been admitted to various psychiatric hospitals all over the country. Though uncommon, the combination of Klinefelter's Syndrome and self-mutilation does seem to exist.

London Hospital

Theresa Christian

London E3

Dear SiRS

We should like to report a similar case to those reported by Professor Priest and his colleagues (Bulletin. July 1984, 8, 140).

The patient is a 32-year-old, married man with documented Klinefelter's Syndrome. He is sterile and presently impotent. He has a sociopathic personality disorder. He has a normal EEG and his IQ is in the dull range of 75-80. He, too, has exhibited transient psychotic features. He has few characteristics of Money's' stereotype Klinefeiter. He more resembles the picture described by Wakeling ${ }^{2}$ with delayed maturation; poor scholastic achievement, marked neurotic traits in childhood, a diagnosis of personality disorder and behaviour which is erratic, impulsive and aggressive.

He has shown a vast array of behaviour problems. These include court appearances and a prison sentence for alcohol related offences and violence and orthopaedic treatment for fractions sustained in fights. He has made multiple appearances in Casualty with self-inflicted lacerations and overdoses, however, none of these have ever been life threatening. At a peak he made six such appearances over a three-week period. He has also been violent towards his wife, hospital staff and occasioned damage to hospital property. Also well documented is a high rate of drug and alcohol abuse in self-mutilators; ${ }^{3.4}$ he abuses both drugs and alcohol.

A further interesting, though difficult, problem he presents is periodic urinary retention of obscure origin. often combined with nocturnal enuresis. This has led to further appearances at Casualty with demands for catheterization. This problem has been extensively, though fruitlessly, investigated both urologically and ncurologically. All psychological approaches to this problem have been defeated by the patient who will, whilst insisting he requires help, systematically destroy 'bell and pads' or sabotage any other programmes. One could speculate that his recurrent demands for catheterization, which is both painful and invasive, constitute a variant of self-mutilation.

His retention is not presently a problem. Attempts at in-patient assessment have without exception ended with violence, suicidal threats or self-discharge. He is currently out of contact with the local psychiatric services.

C. J. Thomas P. TURNER

Leicester General Hospital

Leicester

\section{REFERENCES}

IMONEY. J. (1975) Human behaviour cytogenetics: Review of psychopathology in three syndromes $47 \mathrm{XXY}, 47 \mathrm{XYY}$ and $45 \mathrm{X}$. The Journal of Sex Research, 11, 181-200.

2WAKELING. A. (1972) Comparative study of psychiatric patients with Klinefelter's Syndrome and hypogonadism. Psychological Medicine, 2, 139-54.

${ }^{3}$ Rosenthal. R. J. et al. (1972) The wrist cutting syndrome: The meaning of gesture. American Journal of Psychiary, 128, 1363.

${ }^{4}$ Simpson, M. A. (1975) Symposium on self-injury: Phenomenology of self-mutilation in a general hospital setting. Canadian Psychiatric Association Journal, 20, 429.

\section{The importance of clear directives in community care}

DeAr Sirs

The June issue of the Bulletin contained a letter and statement from the National Schizophrenia Fellowship urging more forward planning in the provision of adequate community services to cope with the proposed discharge of many psychiatric patients back into the community. The same issue also contained Sidney Brandon's review of The Mind Manifesto: $A$ Common Concern, in which he expressed concern about interdisciplinary conflicts, rivalries and self-interests displayed in connection with proposed community services.

After four years working as a community psychiatrist in Edinburgh, I am left in no doubt that we, the psychiatric profession must seriously rethink our own current strategies about delivery of service and our training procedures if we are to take into account the trend towards community care. Inevitably we will have to work more closely, not only with community psychiatric nurses and community-based psychologists, but also with primary care teams, with local authority social workers, and with voluntary workers and the private sector if. as psychiatrists, we are to continue to maintain any role in the joint care of the emotionally and behaviourally disturbed in the community.

I believe we must urgently formulate methods of assisting the transition from our present clinical practice, i.e. hospi- 